\title{
Bite Marks Encountered in Violent Crimes: Punishes Guilty and Safeguards Innocent
}

\author{
Garima Rastogi \\ Forensic Expert, Sherlock Institute of Forensic Science (SIFS India), \\ Email: garima390286@gmail.com
}

\begin{abstract}
The impression left by the teeth on a surface is called as Bite marks. As a physical evidence in a violent crimes it helps in the identification of the accused and hence, offer forensic relevance. Bite mark identification is grounded on the individuality of the dentition, which is used to compare and match with the suspect. DNA collected through the swab over the bite mark helps in DNA Fingerprinting. Therefore Bite mark analysis gives a considerable challenge to Forensic Odontologists (forensic dentist) which comes under Forensic Medicine. The present paper highlights on the analysis of the bite mark and its forensic importance to help the court of law for the identification of culprit and safeguard the person with false allegation.
\end{abstract}

Keywords: Bite Marks, Forensic Dentistry, Physical Evidence, Identification, Analysis

\section{Introduction}

"The criminal may lie through his teeth though the teeth themselves cannot lie" by Furness. Bite marks analysis is ground on principle 'no two mouths are alike'. Bite marks are hence, considered as a valuable alternative to fingerprinting and DNA identification in forensic examinations. American Board of Forensic Odontology defines a bite mark in skin as being a physical alteration in a medium caused by the contact of teeth and specifically as a representative pattern left in an object or tissue by the dental structures of an animal or human. Bite marks left on different parts of the body of female victim by the assailant such as face, neck, thighs, female genital, waist, buttocks and ears while, in males, it can be usually observed over the arms, chest, penis which signifies sign of struggle in violent crimes like sexual assaults, abduction, quarrels, child abuse cases, homicides and sometimes deliberately inflicted to falsely frame someone. Moreover it can be collected on the objects like chewing gum, pencils, pens, cigar, cigarettes, food materials etc. When handled carefully give idea about the perpetrator. Bite mark left on the crime scene generally goes unnoticeable. Therefore, physical evidence, bite mark present at the scene of crime is collected and examined. Dental cast are made for the comparison with the suspect person for the identification. Identification of bite mark is based on class and individual characteristics.

Present paper focuses on the recording, collection and analysis of the bite marks, also restoration of the integrity of the evidence by maintaining proper chain of custody and its importance in an accused identification which safeguards the innocent and punishes the guilty.

\section{Different Types of Bite Marks}

Bite marks are roughly classified as non-human (animal bite marks) and those inflicted by humans. According to the manner of causation, bite marks can be non-criminal (such as love bites) as well as criminal which can further be classified into offensive (upon victim by assailant) and defensive (upon assailant by victim) bite marks. . There are seven types of bite marks observed on the soft tissues; 'Abrasion' (scrape is observed over the skin), 'Haemorrhage' (a profusely bleeding bite), 'Contusion' (a bruise usually observed at the center of the bite mark), 'Incision' (a clean, neat wound), 'Laceration' (a punctured wound), 'Avulsion' (removal of skin due to biting), and 'Artefact' (when a piece of the body, such as an ear lobe, is removed through biting). These are further classified into several types depending upon the pressure applied by the biter; 'Clearly defined' that results due to the application of significant pressure, 'Obviously defined' which is effect of the medium pressure, 'Quite noticeable' results from violent pressure and 'Lacerated' ferociously torn of skin from the body. Bite marks are also found on inanimate object and materials which receive impressions of teeth from biting. Other injuries that often confused with bite mark are: injuries caused by contact with shoe soles, belt buckles, with a domestic iron, injuries from application of defibrillators, saw and tattoos. 


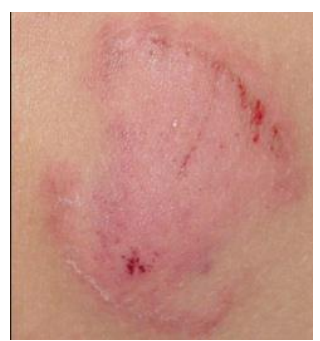

Abrasion Bite Mark

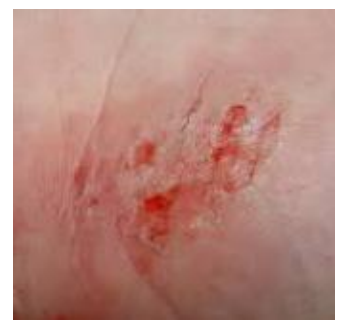

Avulsion Bite mark

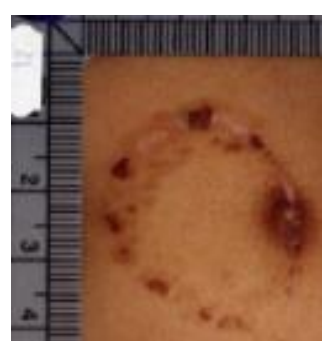

Haemorrhage Bite Mark

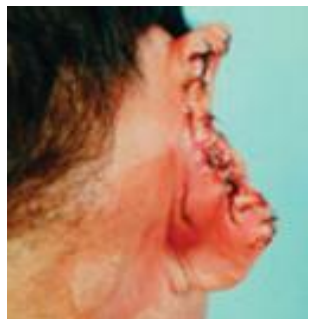

Artefact Bite mark

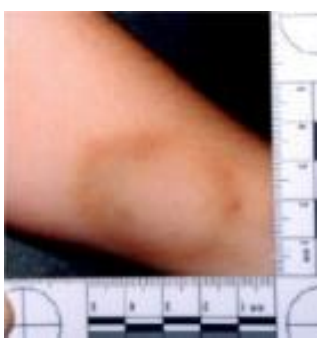

Contusion Bite Mark

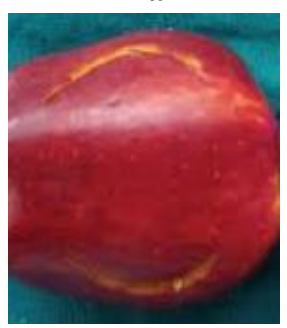

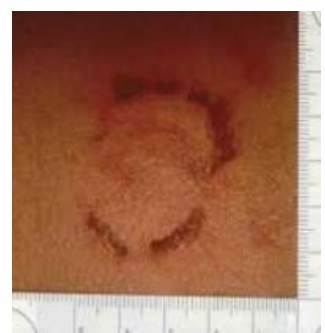

Incision Bite Mark

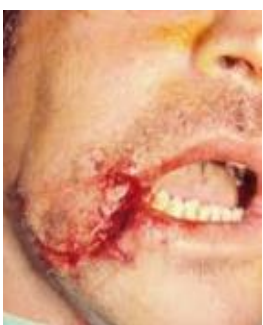

Lacerated Bite Mark

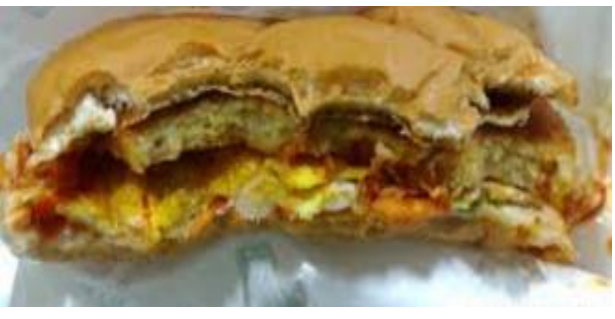

Bite Mark on Food Articles

\section{Collection of Bite Mark Evidence from Victim and Suspect}

The preliminary information documented from

Bite-mark pattern deposited on foodstuffs or upon the victim of an assault or homicide or inflicted by a deceased victim on a living assailant. Bite marks are produced by the force of the teeth, tongue and scrape. The constant force exerted through incisal edges of the anterior teeth or occlusal edges of the posterior teeth results in tooth marks. Brutality of bite mark rest on duration, force applied and grade of movement between tissue and tooth. A human bite mark is characterize by an elliptical or circular injury with individualities of the teeth. If there is a single "C" shaped mark, then only one jaw (lower jaw) was involved whose diameter ranges from $25-40 \mathrm{~mm}$. Contusion is observed at the center of the bite mark when tissues are compressed inward during biting. Tongue pressure is also important for credentials which is applied when material is taken into the mouth and pressed against the teeth/ palatal rugae and tongue thrusting and sucking develops distinguish mark. Tooth scraping involves anterior teeth. Distortion of the bite mark may observed. There are two types of distortions, first, primary distortion based on dynamics of the bite. Secondary distortion includes time related distortion, posture distortion, and photographic distortion. As the time interval after the mark is made is increased, the mark becomes less distinct in both living and dead. In the living, bruising and swelling heals and it wrap a bite so that it does not align properly. In the dead, the body begins to decompose and shrinkage after rigor mortis. Another problem which bite mark evidence faces is that like other sciences (fingerprint analysis and firearm analysis) it is subjective to a person, therefore different expert has different opinion on the same. Hence, photographs are considered to be the best suitable evidence for the examination and comparison of the bite marks in suspicion.

the living or deceased victim is name, age, sex, case no., date, place of incident, name of the examiner followed by the location of bite mark on the part of body, shape of the bite mark such as round, ovoid, crescent and irregular. Further color and size of the mark, both vertical and horizontal dimensions are recorded. Further recording of the bite mark is done through photography during the investigation procedure for the future reference. It is consider as a permanent evidence, as bite mark on living heals with time, whereas in deceased it starts decomposing and deformed. Bite mark in the deceased considerably last longer than a bite mark in living flesh and therefore given lower priority in the investigation. The use of digital camera over traditional once allows the Odontologist to reduce the margin of error and produce life size dimension of the photograph. If much time has lapsed after the mark was made then alternative photographic methods using ultraviolet light can be used to make images of the tips of the penetrated area. Far-away shots are taken to locate the actual position of the bite mark on the object or part of body. Close up photographs of bite marks are taken under high resolution in 1:1 and color films are used to balance the color. Whenever required a color photographic film is used. Linear scale is placed both horizontally and vertically to the bite mark and shots are taken by placing the camera perpendicular to the mark, so as to get real size of the mark. Now a days, ABFO no. 2 scale is used which is "L"shaped scale used to measure specifically bite marks. A scale should be kept on the same plane and adjacent to the bite marks and during the photography of the bite marks, chances of distortion should be negated. Photographs are further used for comparison may be enhanced with different image enhancing software via 
photoshop editor, where bite marks images can be enhanced and made clearer by changing the background colors, contrast, adding filters and then comparing the peculiar features in both the images. To bring out some details that could not be infer by the normal positive print are illuminated under uiltra violet light or infrared. Any type of injury present should be noted. Next, Swabbing is done with the help of sterile cotton ball. The amount of saliva deposited over the bite mark is $0.3 \mathrm{ml}$ which is distributed over $20 \mathrm{~cm}$ over the nearby area. The whole bite mark and adjacent area is swabbed holding cotton ball with a forcep and moving in circular motion. Air dries the cotton by placing it over the slide. Swab material is packed in paper bag, sealed and send it for the examination. Similarly, control samples are prepared without saliva. Blood grouping for antigen is done with mixed agglutination and absorption elution methods. Further, DNA present in the epithelial cells found in the saliva as trace evidence can be typed for individualization. The double swab technique involves and both swabs are sent for the analysis. Moreover, casting of the print is done with the help of plaster of paris or dental stone, if the impression penetrates deeper tissues of the skin. Now a days, rubber base and silicon base compounds are used. Bite mark on foodstuffs maybe long lasting or may deteriorate very rapidly. Therefore, it is imperative that foodstuff be assessed primarily and appropriate preservation measures taken to safeguard that the mark is not lost or degraded in any way

Identification, Analysis and Comparison of Bite Mark: Primary concern is to locate a mark on an object or skin, secondary is to identify whether it is a bite mark or other injury. After recognizing the mark as bite mark, it is important to find whether it of human or non-human (animal) origin. The bite marks left on a victim shall be used to identify the perpetrator. Bite mark identification is grounded on the individuality of a dentition, which is used to compare and match a bite mark to a suspected person. The exact identification of a living person by means of individual traits and characteristics of the teeth and jaws is the basis of forensic science.

Bite marks are compared on the basis of their class and individual characteristics. Class characteristics are used to cut short the number of suspects and may be found that features are common to a group whereas, individual characteristics are peculiar to a person which could not found in the other individual and hence, used to identify an individual. According to the Manual of American Board of Forensic Odontology (ABFO), a class characteristic is a feature or pattern that discriminates a bite mark from the other patterned injuries. It helps to classify the group from which bite mark instigates. A circular or ovoid-shaped injury comprising two opposing arches, which are usually separate from each other. At times these circles or ovoids may be partial, which indicates that the forensic odontologist should exercise caution in their interpretation. Also notice the shape and size of the teeth impression and arch formed on the skin along with the bruises or abrasions. Note down multiple injuries that may be present at different sites, and sometimes may be seen in the same site overlapping or superimposed on each other. Usually, the meeting point is closer to the lower arch than the upper as the teeth of the lower arch move less across the tissue surface when compared to those of the upper arch. If this general feature is not observed, then we may question whether the injury is actually a bite mark. Individual characteristics are the characteristics or features that are unique to an individual. It includes specific features that are found within the class characteristics which signifies an individual variation rather than an expected finding. Shape, size, number and position of the teeth in dental arch differ in every person and, hence consider to be an individual characteristic also some physical and chemical injuries affecting the teeth like missing teeth, abrasion, attrition, erosion, due to poor oral hygiene, and there might be restorations of the carious teeth. Individual characteristics of bite marks are pretentious by peculiarities like muscle function, occlusion, individual tooth movement and TMJ (Temporomandibular joint) dysfunction in the perpetrator. Further, the trace evidence that is DNA present collected after swabbing the bite mark helps in DNA fingerprinting that in turns helps in personal identification. In Forensic dentistry, the most remarkable, difficult and sometimes troublesome challenges encounters is the identification, recovery and analysis of the bite marks with the suspected biters. Due to the curves and other irregularities, the skin is considered as a poor medium for accurate impressions as it produces intrinsic distortion therefore, doubts have been raised about the accuracy of the bite imprint. Thus comparison of a suspect's teeth to bite-mark on a victim's body is prone to error leading to false allegations against person in crimes they did not commit which limits its importance. Unlike fingerprints, which are stable over the course of an individual's life, the dentition is capable of major modifications in configuration, with and without professional intervention. Human dentition uniqueness has not been definitely established. Also a bite mark is not an overall accurate exemplification of the teeth, tongue and jaw movements are also involved. Till date there is no standard comparison procedure for bite marks. Ultimate outcome depends on an examiner's objectivity and methods used.

\section{Conclusion}

Bite mark analysis is a vital aspect of forensic dentistry and shows high significance in solving crimes and helps court of law by identifying the guilty. Despite of few limitations, in rape and violent crimes such evidence is consider as conclusive as DNA and 
fingerprint evidence as its individual and peculiar characteristics give useful clues about the accused and exclusion of an innocent individual under investigation. Therefore, after the location, recording, collection and packaging of the evidence for identification in laboratory a proper chain of custody show be maintained to restore the integrity of the evidence before presenting in front of court, that is proper record should be maintained of all the persons to whom the evidence has been handed and passed on, till it reached to expert for examination in laboratory. Physical bite mark evidence will always play an essential part in criminal investigations. It is recommended that after the comparison of class characteristics like the shape, size and other features of the bite mark found on the victim's body to the suspect dentition. It is necessary to record the individual characteristics to positively identify the perpetrator because class can be common to a group but individual features are individual to a person. Therefore identification requires both class as well as individual characteristics. Recent advancement in the technology through ultra violet lighting to detect human bite marks on rape victim's odontology has proved to be boon. Also blood grouping and DNA sequencing can be done with the secretory elements and epithelial cells found in the saliva present over the bite mark. Bite marks if analyzed accurately not only can ascertain the participation of a particular person or persons in crime but also help in exoneration of the innocent/ acquitted. Hence, in crime scene investigation, dentistry is a tool that is gaining a wider acceptance and every IO is well served by acquainting themselves with the range and scope of services available. To conclude it is rightly said 'while the criminal may lie through his mouth, but his mouth reveal all, and do not lie'.

\section{Case Studies}

The leading case of Florida, in legal history is of Ted Bundy's bite mark case that relied on bite mark testimony, the bite mark evidence recovered on the left buttock of the Levy solved a famous case of Lisa Levy and Martha Bowman murder. On January 15, 1978 two young girls were brutally killed using wooden club. A witness observed a man with cloth covered was running out of the scene. A ferocious and ruthless murder recorded by the investigator. Levy was strangled, beaten on head and was raped. Bowman was strangled and severely beaten on the head. No sign of struggling was found. No solid evidence was found as the scene was wiped off and the tool used in crime was missing. Therefore, Ted Bundy was known for his accuracy and the investigators presumed that Levy and Bowman were Bundy's latest victims. But to prove in court of law you have to have a hard evidence, presumptions don't count in court. Investigators collected evidence such as blood, a few print smudges, and sperm samples which were proved inconclusive. Later Bite mark was recovered which was considered to be the centerpiece of evidence in the trail. Bite mark recovered on the buttock and breast of Lisa Levy was recorded and photographed with the yellow scale in background. Dental impression was taken from the suspects for the comparison with the suspicious bite mark, but Bundy refused. Investigator issued a search warrant that authorized them to obtain the impression in any possible way. Dr. Souviron, an experienced dentist, took the photographs of upper and lower jaw and record the uneven pattern noticed. Dental photographs from the Bundy were then compared with the photographs of the impression on the buttock of the Lisa as it was more prominent than the one found on the breast. Based on the shape of the teeth, sharpness of different teeth, pressure applied, and arrangement of the teeth, as tissues near the impression were destroyed with the time. Therefore, peculiar features were found due to which Bundy sentenced guilty after the expert witness, who explain that the attacker beaten twice keeping his upper jaw at the same position and lower jaw sideways. Death sentence was announced on electric chair.

\section{References}

1. Taylor J. A, Kieser J. A, "Forensic odontology principles and practice", first edition (2016).

2. Bhargava k, Bhargava D, Rastogi P, An overview of Bite Mark Analysis. J Indian Acad Forensic Med; March-2012, vol. 34, 1

3. Kumar A, Yadav Mukesh, Analysis of Bite Mark Evidence. J Indian Acad Forensic Med, June-2012; vol. 34, 2.

4. Verma AK, Kumar S, Identification of a person with the help of Bite mark analysis. Journal of Oral Biology and Craniofacial Research; June-2013; vol. 3, 2.

5. Yadav N, Srivastava PC, Bite marks: An Indispensable Forensic Odontological Evidences in Rape Cases. J Indian Acad Forensic Med, JulySeptember-2014; vol. 36, 3.

6. Thompson AH. Teeth as Means of Identification. 8th ed. Google Book Result, http//www.allaboutforensic-science.com/forensicscience-online.html.

7. MacDonald DG. Bite mark recognition and interpretation. Journal of Forensic Science Society 1974; 14: 229-233.

8. Wagner GN. Scientific Methods of Identification. In: Forensic Dentistry. New York: CRC Press; 1997. pp. 1-36.

9. ABFO, American Board of Forensic Odontology Diplomates Reference Manual; June-2010.

10. Bowers CM. Forensic Dental Evidence: $A n$ Investigator's Handbook. Boston: Elsevier Academic Press; 2004.

11. Vale GL. Dentistry, bite marks and investigation of crime. Journal of California Dental Association 1996; 25: 29-34.

12. Bush MA, Miller RG, Bush PJ, et al. Biomechanical factors in human dermal bite marks in a cadaver model. Journal of Forensic Sciences 2009; 54:16776. 
13. Rothwell RR. Bite marks in forensic dentistry: a review of legal, scientific issues. Journal of American Dental Association 1995; 126: 223-232.

14. Evidence from the Crime Scene- An Overview. Open Access; 2013, vol. 2, 1

15. California innocence project, Bite mark evidence: https://californiainnocenceproject.org/issues-weface/bite-mark-evidence/

16. Ted Bundy, The final bite mark. https://sites.google.com/site/tedbundythelastbitemar k/the-famous-bitemark-case

17. Horswell $J$, The practice of crime scene investigation, 2004 